OPEN ACCESS

Edited by: Claudia Felser,

University of Potsdam, Germany

Reviewed by:

Lena Ann Jäger,

University of Potsdam, Germany Andrea Eyleen Martin-Nieuwland,

University of Edinburgh, UK

*Correspondence: Brian Dillon brian@linguist.umass.edu

Specialty section: This article was submitted to Language Sciences, a section of the journal Frontiers in Psychology

Received: 27 July 2015 Accepted: 08 December 2015 Published: 05 January 2016

Citation:

Dillon $B$, Chow $W-Y$ and Xiang $M$ (2016) The Relationship Between Anaphor Features and Antecedent Retrieval: Comparing Mandarin Ziji and Ta-Ziji. Front. Psychol. 6:1966. doi: 10.3389/fpsyg.2015.01966

\section{The Relationship Between Anaphor Features and Antecedent Retrieval: Comparing Mandarin Ziji and Ta-Ziji}

\author{
Brian Dillon ${ }^{1 *}$, Wing-Yee Chow ${ }^{2}$ and Ming Xiang ${ }^{3}$ \\ ${ }^{1}$ Department of Linguistics, University of Massachusetts Amherst, Amherst, MA, USA, ${ }^{2}$ Department of Linguistics, University \\ College London, London, UK, ${ }^{3}$ Department of Linguistics, University of Chicago, Chicago, IL, USA
}

In the present study we report two self-paced reading experiments that investigate antecedent retrieval processes in sentence comprehension by contrasting the real-time processing behavior of two different reflexive anaphors in Mandarin Chinese. Previous work has suggested that comprehenders initially evaluate the fit between the morphologically simple long-distance reflexive "ziji" and the closest available subject position, only subsequently considering more structurally distant antecedents (Gao et al., 2005; Liu, 2009; Li and Zhou, 2010; Dillon et al., 2014; cf. Chen et al., 2012). In this paper, we investigate whether this locality bias effect obtains for other reflexive anaphors in Mandarin Chinese, or if it is associated specifically with the morphologically simple reflexive ziji. We do this by comparing the processing of ziji to the processing of the morphologically complex reflexive ta-ziji (lit. s/he-self). In Experiment 1, we investigate the processing of ziji, and replicate the finding of a strong locality bias effect for ziji in self-paced reading measures. In Experiment 2, we investigate the processing of the morphologically complex reflexive ta-ziji in the same structural configurations as Experiment 1. A comparison of our experiments reveals that ta-ziji shows a significantly weaker locality bias effect than ziji does. We propose that this results from the difference in the number of morphological and semantic features on the anaphor ta-ziji relative to ziji. Specifically, we propose that the additional retrieval cues associated with ta-ziji reduce interference from irrelevant representations in memory, allowing it to more reliably access an antecedent regardless its linear or structural distance. This reduced interference in turn leads to a diminished locality bias effect for the morphologically complex anaphor ta-ziji.

Keywords: sentence processing, Mandarin Chinese, long-distance reflexives, working memory, referential processing

\section{INTRODUCTION}

Anaphoric expressions such as pronouns (e.g., him, he), reflexives (e.g., himself), and anaphoric definite descriptions (e.g., the boy) have been widely studied in both linguistic and psycholinguistic traditions. Linguists have long been concerned with how the interpretation and syntactic distribution of referring expressions are determined (Chomsky, 1981; Heim, 1982; Elbourne, 2008; a.o.). Psycholinguists have studied anaphoric expressions both as a window into how 
comprehenders organize a text, and as a window into the working memory mechanisms that support sentence-level and discourselevel language comprehension (Kintsch, 1975; Gernsbacher, 1989; Greene et al., 1992; Myers and O’Brien, 1998; Foraker and McElree, 2011; Kush, 2013; Sturt, 2013; Dillon, 2014; a.o).

In the present work, we pursue a research question at the intersection of these two traditions. We ask how the form of a referring expression is related to the processing mechanisms that comprehenders use to assign it a referent. To this end, we contrast the processing of two closely related reflexive anaphors in Mandarin Chinese. Specifically, we compare the processing behavior of the morphologically simple reflexive ziji to that of the morphologically complex reflexive ta-ziji. In two selfpaced reading experiments, we investigate the degree to which each anaphor exhibits a locality bias, a processing advantage (or preference) for syntactically local antecedents over more distant ones. Our empirical goal is to investigate the effect of morphological complexity on the processing of an anaphoric expression, with special attention to how morphology modulates the degree to which an anaphor will exhibit locality biases in processing. We interpret our results with respect to a theoretical model of anaphoric processing developed in other work (Dillon et al., 2014). To foreshadow our empirical and theoretical conclusions: our experimental findings suggest that morphologically complex anaphors in Mandarin Chinese show a diminished locality bias in comparison to morphologically simple ones, a finding that we attribute to how the processor makes use of the richer morphological feature content of morphologically complex anaphors in retrieving an antecedent from memory.

\section{LONG DISTANCE REFLEXIVES AND LOCALITY EFFECTS}

In recent years, there have been a number of experimental investigations into the real-time processing behavior of the Mandarin Chinese long-distance reflexive ziji. Ziji is a morphologically simplex reflexive, literally meaning self (Huang et al., 2009). Ziji is a long-distance reflexive, unlike English reflexives which must be bound within their immediate tensed clause (their binding domain; Chomsky, 1981). Long-distance reflexives are so called because their binding domain is larger than their immediate tensed clause, although the exact size of their expanded domain varies across languages (see Büring, 2005). For Mandarin ziji, it appears that the binding domain is the entire root clause in which $z i j i$ is found (Tang, 1989; Xue et al., 1994; Huang and Liu, 2001; Büring, 2005; Huang et al., 2006, 2009). To take one example, in (1) ziji may be bound either by the subject of its immediate clause Lisi, or by the subject of the higher (root) clause Zhangsan (subscripts are used to indicate acceptable coindexation):

(1) 张三 说 李四弄伤了 自己

Zhangsan $_{\mathrm{j}}$ shuo Lisi $_{\mathrm{i}}$ nongshang-le $\mathrm{ziji}_{\mathrm{i} / \mathrm{j}}$

Zhangsan say Lisi harm-PERF self

"Zhangsan says that Lisi harmed him/herself"
Ziji requires an animate antecedent (Tang, 1989; Xue et al., 1994; Huang and Liu, 2001), and receives an interpretation analogous to English reflexive forms. Ziji does not bear any overt morphological features, however, and so may take antecedents regardless of their gender, number, or person features.

Given the possibility of long-distance binding, it is interesting to note that many experimental studies have shown that comprehenders show a locality bias when processing ziji, preferring or more easily processing antecedents in their local clause over antecedents found in more distant clauses. For example, Li and Zhou (2010) conducted an ERP experiment in Mandarin, measuring the electrophysiological response to the anaphor "ziji” in examples like (2):
(2) a. 小李 让 小张 不要 伪装 自己 Xiaoli $_{\mathrm{i}}$ rang Xiaozhang buyao weizhuang $\mathrm{ziji}_{\mathrm{i} i / \mathrm{j}}$. Xiaoli ask Xiaozhang not disguise ziji. "Xiaoli asked Xiaozhang not to disguise himself."
b. 小李 让 小张 不要 牵连 自己

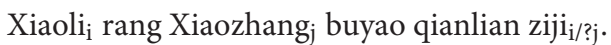 Xiaoli ask Xiaozhang not embroil ziji.
"Xiaoli asked Xiaozhang not to embroil him."

Li and Zhou observed a larger positivity (P300/P600) at ziji when the semantics of the verb created a bias toward a longdistance reading of the reflexive, as in (2b), compared to when the meaning of the verb biased comprehenders toward a local reading of the reflexive, as in (2a).

Cross-modal priming studies point to a similar advantage for local antecedents over long-distance antecedents. Gao and colleagues (Gao et al., 2005; Liu, 2009) presented participants with spoken sentences of the form in (1). Upon reaching the sentence-final ziji, participants were presented with a visual probe word. When the probe was presented immediately after the anaphor, participants recognized probes that were semantic associates of a local antecedent more quickly than they did probes associated with long-distance antecedents; this locality advantage disappeared or reversed at slightly longer SOAs (160 and $370 \mathrm{~ms}$ ).

Using a different experimental paradigm, Chen et al. (2012) showed using self-paced reading that locally bound ziji was read more quickly than long-distance bound ziji. These authors leveraged the observation that ziji requires an animate antecedent to create the pair of experimental sentences in (3) (brackets are used to indicate tensed clause boundaries):

(3) a. 反对派领袖表示这个声明 Fanduipai-lingxiu $_{i}$ biaoshi [zhe-ge shengming $_{j}$ 在抗议失控 的时候告诫了自己的

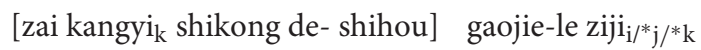
党员

de dangyuan] opposition-leader say [this- $\mathrm{cl}$ announcement [at protest out.of.control time] warn- PERF ziji de party.member] "The opposition leader said that this announcement warned his party members when the protest was out of control" 


\section{b. 这个声明表示 反对派领袖} Zhe-ge shengming biaoshi [fanduipai- lingxiu $_{j}$ 在抗议失控的时候告诫了自己的 [zai kangyi $\mathrm{i}_{\mathrm{k}}$ shikong de-shihou] gaojie-le ziji $*_{\mathrm{i} / \mathrm{j} /} /{ }_{\mathrm{k}}$ 党员

de dangyuan]

this-CL announcement say [opposition-leader [at protest out.of.control time] warn-PERF ziji de party.member]

"The announcement said that the opposition leader warned his party members when the protest was out of control"

In these examples, ziji is the possessor of the direct object NP and it appears immediately after the embedded verb. In (3a), the only animate, c-commanding antecedent is fanduipai-lingxiu, "opposition leader." Thus, in this example, ziji must take a long-distance antecedent in the immediately higher clause. In contrast, the embedded subject in (3b) is the only animate and c-commanding antecedent, and so ziji must take a syntactically local antecedent. In this paradigm, the difference in reading times between $z i j i$ in (3a) and (3b) is taken to indicate the difficulty of constructing a long-distance $z i j i$ interpretation in (3a). Chen and colleagues observed a small but reliable RT slow-down in reading times at the region following $z i j i(d e)$ in (3a) relative to (3b), suggesting more difficulty in constructing a long-distance than local interpretation of $z i j i$. This result was subsequently replicated in an eye-tracking while reading study, using direct object $z i j i$ in place of possessive $z i j i$, and without an adverbial clause intervening between the subject and the verb (Jäger et al., 2015; Experiment 2).

Dillon et al. (2014) asked whether the locality bias associated with ziji reflected a difference in processing speed for accessing long-distance antecedents, or simply a difference in processing accuracy associated with long-distance antecedents. For example, it is possible that the memory trace of a distant antecedent is of relatively poor quality compared to that of a local antecedent, perhaps due to memory decay processes. Such a difference in the representational quality of the antecedent could have given rise to the locality bias effect observed in previous studies, without any difference in processing speed. Alternatively, it may be that comprehenders simply take more time to access a long-distance antecedent, such that local antecedent positions have a temporal advantage compared to more structurally or linearly distant positions. Simple response time measures cannot tease these possibilities apart (see McElree, 2006). In order to ask this question, Dillon and colleagues used the multiple-response speed-accuracy tradeoff (MR-SAT) technique to investigate sentences similar to those in (3). The (MR-)SAT technique involves eliciting behavioral responses at a series of pre-defined response deadlines. This allows the researchers to chart how accuracy on a response measure grows as a function of time, giving a full picture of the time-course of processing. Importantly, the resulting SAT function may be separated into independent measures of processing speed and processing accuracy. Dillon et al.'s results indicated that the difference between local and long-distance binding was reflected in the rate parameter of the SAT function, suggesting that comprehenders took longer to retrieve long-distance antecedents for ziji than local antecedents.

Thus, a growing body of evidence suggests that despite the formal possibility of long-distance antecedents for ziji, comprehenders experience relatively more processing difficulty when $z i j i$ 's antecedent is not local. Furthermore, this locality bias seems to reflect a temporal advantage for local antecedents over long-distance antecedents: comprehenders more rapidly access local antecedent positions than long-distance positions.

\section{ZIJI AND TA-ZIJI}

Although previous research on ziji provides much evidence for a locality bias associated with $z i j i$, it is not known how general this locality bias is. It is possible that a locality preference is a general property of long-distance reflexive anaphors. This might be expected if zijis locality bias was simply a reflection of the temporal or linear proximity of a local antecedent. In this case, we might expect all reflexive forms that can find an antecedent outside of their immediate clause to show comparable locality bias. On the other hand, it may be the case that the locality bias is rooted in some other specific property of $z i j i$. For example, it may be the case that $z i j i$ is lack of overt morphological features causes comprehenders to rely more heavily on positional cues when identifying an antecedent, which could lead to a preference for structurally local antecedents. If this is true, then we might expect the presence of locality bias effects to vary from anaphor to anaphor, depending on the surface form of the anaphor.

Mandarin grammar allows us to ask this question, because reflexive anaphors in Mandarin come in two forms: the morphologically simple, "bare" reflexive ziji, and morphologically complex anaphors. An example of a morphologically complex anaphor is ta-ziji, which consists of a third singular pronoun along with the bare reflexive (e.g. "heself"). Other morphologically complex reflexives may be formed by combining other pronouns with ziji (e.g., wo-ziji, myself; $n i-z i j i$, yourself), although here we focus on the third person singular form ta-ziji. Ta-ziji has a distribution that partially overlaps with ziji. For instance, when the antecedent of the anaphor is in the local clause, $t a-z i j i$ and $z i j i$ are interchangeable:

\section{(4) 李四 弄伤了 自己/他自己 \\ Lisi $i_{\mathrm{i}}$ nongshang-le ziji $\mathrm{i}_{\mathrm{i}} / \mathrm{ta}-\mathrm{ziji} \mathrm{i}_{\mathrm{i}}$ \\ Lisi harm-PERF self / 3sg-self \\ "Lisi harmed himself"}

The morphological differences between $z i j i$ and ta-ziji could lead to processing differences, because there are reasons to suspect that the addition of an overt pronoun to form a morphologically complex anaphor will yield richer cues for purposes of identifying an antecedent. First, the orthographic representation of the pronoun overtly provides gender and personhood cues: 他 (tā) is used for human male referents, 她 (tâ) is used for human female referents, and 它 (tā) is reserved for non-human or gender-neutral referents. These forms are 
distinguished orthographically, but they are not distinguished phonologically. In addition, the use of an overt pronoun is statistically more likely for gendered human antecedents than for non-human or gender neutral antecedents. A search of the Google Books corpus for simplified Chinese in the last 50 years reveals that approximately $73-80 \%$ of tokens of the third person singular pronoun refer to explicitly gendered human antecedents.

If this is correct, then we might say that ta-ziji has more features that can be used as cues to identify an antecedent when processing the reflexive. In particular, the addition of a pronominal form contributes humanness cues (i.e., [+human]) and gender cues. In contrast, the reflexive form ziji may only contribute animacy cues, because this is the only restriction that it places on potential antecedents. An interesting question to ask is whether the relatively more specified feature content of ta-ziji will lead to diminished locality bias for ta-ziji compared to $z i j i$. If the locality bias associated with ziji reflects solely the influence of standard memory variables, such as decay or interference, then we might not expect the size or magnitude of the effect to vary with the surface form of the anaphor. If, on the other hand, the surface form of the anaphor contributes additional cues to identifying an antecedent, then locality bias might be diminished or eliminated for anaphors whose surface form bears more overt features. Thus, in the present study we aim to provide a head to head comparison of the locality bias associated with morphologically simple and morphologically complex anaphors, in an attempt to determine how generally locality bias is in the processing of anaphors in Mandarin.

Unfortunately, a direct comparison of the locality effects for $z i j i$ and $t a-z i j i$ is somewhat complicated by the fact that they do not have identical syntactic distributions. In contrast to $z i j i$, the size of ta-ziji's binding domain is a matter of some controversy. Huang et al. (2009) reported that it must be bound within its immediate tensed clause, like English himself. However, Pan $(1998,2000)$ argued that the binding domain of ta-ziji is fixed by the closest accessible animate antecedent, such that $t a-z i j$ can be bound outside of its local clause if the local subject is inanimate. What is clear is that ta-ziji places greater restrictions on long-distance antecedents than does ziji, and for this reason it is sometimes classified as a purely local reflexive in Mandarin (Huang et al., 2009). Because of the lack of clarity in the binding domains associated with these two reflexives, it is not ideal to compare these reflexives in the same embedding configurations used in previous studies (Chen et al., 2012; Dillon et al., 2014; Jäger et al., 2015).

Instead, we compared the behavior of ziji and ta-ziji in environments where they do have reliably overlapping distributions. For both ziji and ta-ziji the c-command relation that regulates binding in English (Chomsky, 1981) appears to be too restrictive. Instead, antecedents that do not strictly ccommand these anaphors may be grammatically available, as in (5) (Tang, 1989):

(5) 张三 的骄傲 害了自己/他自己

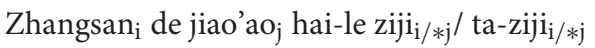

Zhangsan de arrogance harm-PERF ziji / 3sg-ziji

"Zhangsan's arrogance harmed him.”
In (5), the antecedent Zhangsan is embedded inside the subject, and hence does not c-command the anaphor. Nonetheless, in this configuration it is available to bind the reflexive. The structural relationship between Zhangsan and ( $t a-) z i j i$ in (5) is referred to as subcommand (Tang, 1989; Huang and Tang, 1991). An NP is said to subcommand the anaphor if it is contained within an NP in subject position that c-commands or subcommands the anaphor (Tang, 1989).

However, it is important to note that subcommanding antecedents are not freely available. Instead, a subcommanding antecedent is only available when no animate c-commanding or subcommanding antecedent is structurally closer to ziji. Thus, when the subject head noun is animate, subcommanding antecedents are grammatically blocked as in (6):
(6) 张三
的小孩 害了自己/他自己
Zhangsan $_{\mathrm{i}}$ de xiaohai ${ }_{\mathrm{j}}$ hai-le $\mathrm{ziji}_{\mathrm{i}} / \mathrm{j} /$ ta-ziji ${ }_{\mathrm{i}} / \mathrm{j}$
Zhangsan de son harm-PERF ziji / 3sg-ziji
"Zhangsan's son harmed himself."

As ziji and ta-ziji distribute similarly in subcommanding environments, we may compare the processing of ziji and ta-ziji in configurations like (7):

(7) a. 张太太 经常 光顾 的 那个 [Zhang taitai ${ }_{i}$ jingchang guanggu de] na-ge 时装店上个星期 把 自己/她自己

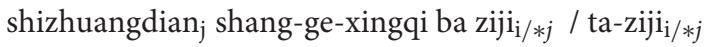
不小心 弄伤了

bu xiaoxin nongshang-le.

Mrs. Zhang often visit DE that-CL boutique last-week ba self / 3sg-self not careful harm-PERF.

"The boutique that Mrs. Zhang often visits carelessly harmed her last week."

b. 媒体 报道 的 那个女裁缝 上个星期

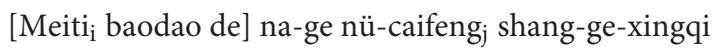

把自己/他自己不小心 弄伤了

ba $\mathrm{ziji}_{*} \mathrm{i} / \mathrm{j} / \mathrm{ta}-\mathrm{zij} * \mathrm{i} / \mathrm{j}$ bu xiaoxin nongshang-le.

Media report-on DE that-CL seamstress last-week ba self / 3 sg-self not careful harm-PERF.

"The seamstress that the media reported on carelessly harmed herself last week."

These examples have an object extracted relative clause (e.g., "that the media reported on") modifying a subject noun (e.g., na-ge nü-caifeng "that seamstress"). This structure creates two subject positions that could in principle bind an anaphor: the local subject position inside the matrix clause, and a distant subject position inside the relative clause. Given the licensing constraints on ziji and ta-ziji, we expect that both the local subject na-ge nü-caifeng "that seamstress" in (7b) and the long-distance subject Zhang taitai "Mrs Zhang" in (7b) should be grammatically accessible antecedents. However, these two antecedents differ in their structural and linear distance from the reflexive. The subcommanding antecedent Mrs. Zhang in (7a) is a long-distance antecedent because it is linearly and structurally more distant from the anaphor than the local antecedent na-ge nü-caifeng in 
(7b). For this pair of conditions, then, a locality effect should present as increased reading times on the anaphor in (7a) compared to (7b).

We now present two experiments that investigate $z i j i$ and $t a-$ $z i j i$ in Mandarin Chinese. Our goal in these experiments was to compare the processing profile of these two anaphors on a number of different dimensions. First, and most importantly, we ask whether both $z i j i$ and ta-ziji show locality effects of comparable magnitude in online sentence comprehension. In addition, we ask whether the processing of both ziji and ta-ziji is equally affected by the presence of multiple feature-matched antecedents. Previous research suggests that the presence of multiple, feature-matched antecedents may cause processing difficulty (the multiple match effect of Badecker and Straub, 2002), although this effect has not be observed in all studies (e.g., Clifton et al., 1999).

\section{EXPERIMENT 1}

\section{Participants}

Forty-one students from the University of Maryland community participated in the experiment. One participant was removed prior to analysis due to low comprehension question accuracy (see below). All participants were native Mandarin Chinese speakers from mainland China, and all had normal or corrected-to-normal vision. They were paid $\$ 10$ for their participation in the experiment. Experimental sessions lasted approximately $45 \mathrm{~min}$. Participants gave informed consent under an experimental protocol approved by the University of Maryland Institutional Review Board.

\section{Stimuli}

We created stimuli with the sentence structure in (7). We orthogonally manipulated the animacy of the local subject position and the embedded subject position, yielding four experimental conditions. These conditions are summarized in (8).

\section{a. LOCAL MATCH:}

\section{媒体 报道 的 那个 女裁缝 上个星期把}

Meiti/ baodao de/ na-ge/ nücaifeng/ shang-ge-xingqi/ ba/

自己不小心 弄伤了

ziji/ bu xiaoxin/ nongshang-le.

Media/ report-on DE / that-CL / seamstress/ last-week/ BA/ self/ not careful/ harm-PERF.

"The seamtress that the media reported on carelessly harmed herself last week."

\section{b. DISTANT MATCH:}

\section{张太太 经常 光顾 的 那个 时装店}

Zhang taitai/ jingchang guanggu de/ na-ge/ shizhuangdian/ 上个星期把自己不小心 弄伤了

shang-ge-xingqi/ ba/ ziji/ bu xiaoxin/ nongshang-le.

Mrs. Zhang/ often visit DE / that-CL / boutique/ last-week/ BA/ self/ not careful/ harm-PERF.
"The boutique that Mrs. Zhang often visits carelessly harmed her last week."

c. MULTIPLE MATCH:

张太太经常 光顾 的 那个女裁缝

Zhang taitai/ jingchang guanggu de/ na-ge/ nücaifeng/

上个星期把自己不小心弄伤了

shang-ge-xingqi/ ba/ ziji/ bu xiaoxin/ nongshang-le.

Mrs. Zhang/ often visit DE / that- CL/ seamstress/ last-week/ $\mathrm{BA} /$ self/ not careful/ harm-PERF.

"The seamstress that Mrs. Zhang often visits carelessly harmed her/herself last week."

\section{d. NO MATCH:}

媒体 报道 的 那个 时装店 上个星期

Meiti/ baodao de/ na-ge/ shizhuangdian/ shang-ge-xingqi/

把自己不小心 弄伤了

ba/ ziji/ bu xiaoxin/ nongshang-le.

Media/ report-on DE/ that-CL/ boutique/ last-week/ BA/ self/ not careful/ harm-PERF.

"The boutique that the media reported on carelessly harmed her last week."

The paradigm employed here thus followed Chen et al. (2012), Dillon et al. (2014), and Jäger et al. (2015) in using animacy to manipulate the binding possibilities for ziji. In the $L O C A L$ MATCH and DISTANT MATCH conditions, the antecedent of $z i j i$ is the animate subject. In the NO MATCH condition, there is no intra-sentential antecedent for ziji. In the MULTIPLE MATCH condition, the local subject na-ge nü-caifeng "that seamstress" is the only grammatically available antecedent of ziji. In this condition, the animate local subject blocks access to the distant subject Mrs. Zhang; therefore, the interpretation of ziji is not ambiguous in the MULTIPLE MATCH condition (see Tang, 1989).

The primary comparison of interest for the present purposes is the difference in reading times between the LOCAL MATCH and DISTANT MATCH conditions at the anaphor. The MULTIPLE $M A T C H$ and NO MATCH conditions were included for two reasons. First, the factorial manipulation of the animacy of the two subject positions allows us to dissociate effects of interest from simple effects of local or distant subject animacy. Second, the inclusion of the MULTIPLE MATCH conditions allows us to estimate any reading time effects associated with multiple feature-matched antecedents (the multiple match effect, Badecker and Straub, 2002). The inclusion of the NO MATCH condition serves as a control. This allows us to evaluate whether readers were indeed attempting to find an antecedent for ziji; if this is the case, then the failure to find an appropriate antecedent in this condition should lead to longer reading times.

The distant (sub-commanding) antecedent position was always the subject of an object relative clause that modified the main clause subject. Owing to the head-final order of noun phrases in Mandarin Chinese, this embedded subject (distant antecedent) is both structurally and linearly further away from 
the anaphor than the main clause subject (local antecedent). The local antecedent always followed the relative clause verb and the relativizing particle $d e$. In order to construct plausible and natural sentences, the predicate inside the relative clause was different for animate (8a-c; e.g., "that Mrs. Zhang often visits") and inanimate ( $8 \mathrm{~b}-\mathrm{d}$; "that the media reported on") relative clause subjects. The main clause predicate was constant across conditions.

In order to avoid having the critical word (the anaphor) in sentence-final position, the $b a$ construction was used, because this construction has an S-ba-O-V word order (in contrast to the canonical SVO word order of Mandarin). A temporal adverbial was placed between the main clause subject (the local antecedent) and the $b a$-marked $z i j i$ to ensure that they were not adjacent to each other. A manner adverbial was placed between ziji and the main clause verb in order to provide an extra spillover region.

Eighteen sets of experimental items were produced, and distributed into four lists in a pseudo-Latin square fashion. They were combined with 77 fillers, including materials from an unrelated experiment, for a total of 95 sentences. The ratio of acceptable-to-unacceptable sentences varied slightly from list to list due to the pseudo-Latin square procedure, but remained between 83 and $85 \%$ acceptable. The fillers included 10 sentences that contained $b a$ followed by non-anaphoric NPs in order to prevent participants from associating $b a$ with $z i j i$ within the experiment.

\section{Procedure}

Sentences were presented using a moving-window self-paced reading paradigm, using the Linger software (Rohde, 2003). Each sentence was presented in black characters on a white screen, and no sentence was more than one line long. All sentences were presented using simplified Chinese characters. The sentences were segmented into 9 regions according to native speaker intuitions about where best to insert boundaries [regions are indicted by slashes in (8)]. This procedure resulted in regions that ranged from one character (e.g., ba) to 6 characters (e.g., yishuticaoguanjun, "gymnastics champion").

Sentences initially appeared as a series of dashes that obscured the entire sentence. Participants pressed the space bar to present the first region, and each subsequent space bar press masked the current region and triggered presentation of the subsequent region. Reaction times between button presses were recorded. After approximately 50\% of the filler sentences, a Yes/No comprehension question was presented in its entirety on the screen, and participants were instructed to press one of two buttons to indicate their response. Feedback was given for incorrect responses. The critical ziji sentences never were followed by comprehension questions.

In the analyses below we refer to the region containing ziji as the critical region, and the region that follows (e.g., bu xiaoxin) as the spillover region.

\section{Statistical Analysis}

We performed a single statistical analysis over the pooled data in Experiments 1 and 2, which we present after Experiment 2. Reaction time data from both experiments were analyzed using linear mixed effects models with three critical experimental contrasts. Taking the LOCAL MATCH condition as the baseline, we defined the Locality contrast as the difference between the DISTANT MATCH condition and the LOCAL MATCH condition. As in previous studies (Chen et al., 2012; Dillon et al., 2014; Jäger et al., 2015), this contrast is interpreted as the penalty associated with long-distance binding of the anaphor. We further defined the Multiple Match contrast as the difference between the MULTIPLE MATCH condition and the LOCAL $M A T C H$ condition; this contrast is interpreted as the penalty associated with having multiple NPs that matched the features of the anaphor. Lastly, we defined the No Antecedent contrast as the difference between the LOCAL MATCH condition and the NO MATCH conditions. Each of these contrasts was coded with treatment coding, treating $L O C A L M A T C H$ as the baseline. These experimental contrasts were shared across Experiments 1 and 2. In addition to these fixed effects, we further included Experiment as a fixed effect with treatment coding, treating Experiment 1 as the baseline. Lastly, to test for differences in our experimental contrasts across experiments, we included terms for the interaction of Experiment with each experimental contrast.

Because our linear mixed effects models assume a normallydistributed response, we applied the Box-Cox procedure to reaction times at the regions we analyzed to determine a transformation that would yield a normally distributed response variable (Box and Cox, 1964). This procedure suggested a transformation in-between a negative reciprocal transform and a logarithmic transformation. Exploratory data analyses revealed that the qualitative pattern of results did not change under different transformations, and so we present the results of linear mixed effects models fit to logarithmically transformed reading time data. We adopted a "maximal" random effects structure, including random intercepts and random slopes for all fixed effect parameters within both subject and item grouping factors where possible (Barr et al., 2013). If the full model failed to converge, we removed random correlations but retained random slopes for all fixed effects.

Because of the pseudo-Latin square procedure, the number of sentences within each condition was not balanced within subjects. To test for any effects this imbalance may have had, we performed log-likelihood ratio tests of models with and without a fixed effect for experimental list. If log-likelihood tests indicated an effect of list, we performed further model comparisons to determine if the effect of list interacted with our experimental fixed effects.

In constructing the materials, we did not attempt to control the length or frequency of the subject noun phrases within items. However, as it has been shown that antecedent frequency is inversely correlated with reading times on anaphoric expressions (Van Gompel and Majid, 2004), we included antecedent frequency and antecedent length for both embedded and matrix subject positions as fixed effect control predictors in all mixed effects models. Antecedent frequency was estimated using the SUBTLEX Chinese corpus (Cai and Brysbaert, 2010). Many of our antecedent phrases were noun-noun compounds that were unattested in the corpus (e.g., laladuiyuan, "cheerleading squad member"). If the entire compound phrase was unattested, we 
TABLE 1 | Mean acceptability ratings in Experiment 1.

\begin{tabular}{lccc}
\hline LOCAL MATCH & DISTANT MATCH & MULTIPLE MATCH & NO MATCH \\
\hline $5.2(0.3)$ & $4.4(0.3)$ & $4.8(0.3)$ & $3.5(0.3)$
\end{tabular}

Parentheses represent standard error by participants, corrected for between-participant variance (Bakeman and McArthur, 1996).

used frequency of the head noun. Length was entered into the model as the number of characters of the head noun in the subject phrase. Both antecedent frequency and length were centered before being entered into the model.

Analysis was performed for three regions of the experimental sentences: the pre-critical region $b a$, the critical region $z i j i$, and the spillover region [e.g., bu xiaoxin in (8)].

\section{Results \\ Offline Judgments}

Prior to Experiment 1, we gathered offline acceptability judgments of all experimental materials. All experimental stimuli, including fillers, were entered into the online experimental platform IbexFarm (Drummond, 2011). Twenty-two native Mandarin speakers were recruited from Beijing Normal University. They were directed to a web address that hosted the offline naturalness judgment questionnaire and they were asked to rate each experimental stimulus on a scale from 1 (not natural) to 7 (very natural).

The results of this offline judgment study are presented in Table 1. These data were analyzed using linear mixed effects modeling, with fixed effects for matrix subject animacy, distant subject animacy, and their interaction. This analysis revealed a main effect of local NP animacy (Est $=-1.09 \pm 0.25, t=-$ 4.3 ), and an interaction of local and distant NP animacy (Est = $-1.29 \pm 0.38, t=-3.45$ ). There were lower acceptability ratings for both conditions with a local inanimate subject (DISTANT MATCH and NO MATCH). However, a post-hoc comparison between these two conditions revealed that average ratings were significantly lower in the NOMATCH condition than in the DISTANT MATCH condition ( $\overline{\mathrm{x}}=-0.9,95 \% \mathrm{CI}$ : $[-1.4,-0.4])$.

\section{Comprehension}

One participant was removed from further analysis due to low accuracy (less than 70\% accurate). After this exclusion, accuracy on the comprehension questions in Experiment 1 averaged $87 \%$ across participants, indicating that the participant attended to the stimuli. Across participants, accuracy ranged from 73 to $98 \%$.

\section{Reading Times}

Raw mean reading times in Experiment 1 are presented in Table 2 and in Figure 1.

\section{Discussion}

The results of the offline judgment experiment revealed that raters assigned lower ratings to sentences where there was not a local antecedent for $z i j i$. The lowest ratings were given to the NO MATCH condition, presumably reflecting the unacceptability that results from the lack of an intra-sentential antecedent.
Interestingly, the DISTANT MATCH condition was rated lower than the LOCAL MATCH and MULTIPLE MATCH conditions. This penalty is consistent with the presence of a locality effect. This conclusion is supported by independent evidence that the acceptability of grammatical sentences is reliably modulated by the length of a binding dependency (Sprouse et al., 2011). However, it is also possible that this reflects relative unacceptability that results from having an inanimate matrix subject. Critically for the present purposes, the DISTANT $M A T C H$ condition was rated as more acceptable than the NO $M A T C H$ condition, consistent with the claim that the distant subject is grammatically accessible as an antecedent for ziji (Tang, 1989; Huang and Tang, 1991).

The results of the self-paced reading experiment suggest a locality effect in the reading times, with the DISTANT MATCH condition being read $41 \mathrm{~ms}$ more slowly than the LOCAL $M A T C H$ condition at the critical region, and 215 ms more slowly in the spillover region. If reliable, this finding would extend the locality bias effect observed in previous experiments to the subcommanding configuration tested here (Chen et al., 2012; Dillon et al., 2014; Jäger et al., 2015). The data also suggest numerically smaller effects of the Multiple Match contrast and the No Antecedent contrast: in the spillover region, reading times were $81 \mathrm{~ms}$ longer in the MULTIPLE MATCH condition than in the LOCAL MATCH condition, and $84 \mathrm{~ms}$ longer in the NO $M A T C H$ condition than in the LOCAL MATCH condition.

Before further interpreting the data in Experiment 1, we present the results of Experiment 2.

\section{EXPERIMENT 2}

Experiment 2 was identical to Experiment 1 in all major respects, except that Experiment 2 investigates the processing of the complex anaphor ta-ziji.

\section{Participants}

Seventy students from the University of Maryland community participated in the experiment. All participants were native Mandarin Chinese speakers from mainland China, and all had normal or corrected-to-normal vision. They were paid $\$ 10$ per hour for their participation in the experiment. Participants gave informed consent under an experimental protocol approved by the University of Maryland Institutional Review Board.

\section{Stimuli}

The materials were largely identical to those from Experiment 1. Two important changes were made to these materials. First, all instances of $z i j i$ were replaced with $t a-z i j i$. The materials were additionally modified so that within an experimental item set, the animate nouns in each position were of the same gender. This was done to ensure that both NPs in the MULTIPLE MATCH condition matched the features of the reflexive. This change was necessary because $t a$ orthographically marks gender. Half of the revised materials had male nouns, and the other half had female nouns.

All other aspects of the stimuli, including the fillers and comprehension questions, were identical to Experiment 1. 
TABLE 2 | Mean reading times per region in Experiment 1.

\begin{tabular}{|c|c|c|c|c|c|c|c|c|c|}
\hline & 1 & 2 & 3 & 4 & 5 & 6 & 7 & 8 & 9 \\
\hline LOCAL MATCH & $762(45)$ & $731(35)$ & $638(40)$ & $849(80)$ & 703 (35) & $564(30)$ & $448(28)$ & $522(26)$ & $615(35)$ \\
\hline DISTANT MATCH & $728(74)$ & $644(24)$ & $599(27)$ & $914(90)$ & 715 (29) & $525(28)$ & 489 (25) & $737(35)$ & $847(81)$ \\
\hline MULTIPLE MATCH & $681(38)$ & 706 (66) & $546(24)$ & $780(58)$ & 767 (37) & $642(81)$ & $467(25)$ & $603(35)$ & $695(57)$ \\
\hline NO MATCH & $825(71)$ & $803(44)$ & $614(53)$ & $669(44)$ & $784(43)$ & $592(31)$ & $541(60)$ & $606(30)$ & $766(51)$ \\
\hline
\end{tabular}

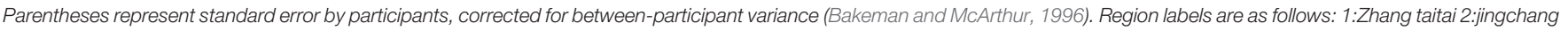
guanggu de 3:na-ge 4:shizhuangdian 5:shang-ge-xingqi 6:ba 7:ziji 8:bu xiaoxin 9:nongshang-le.

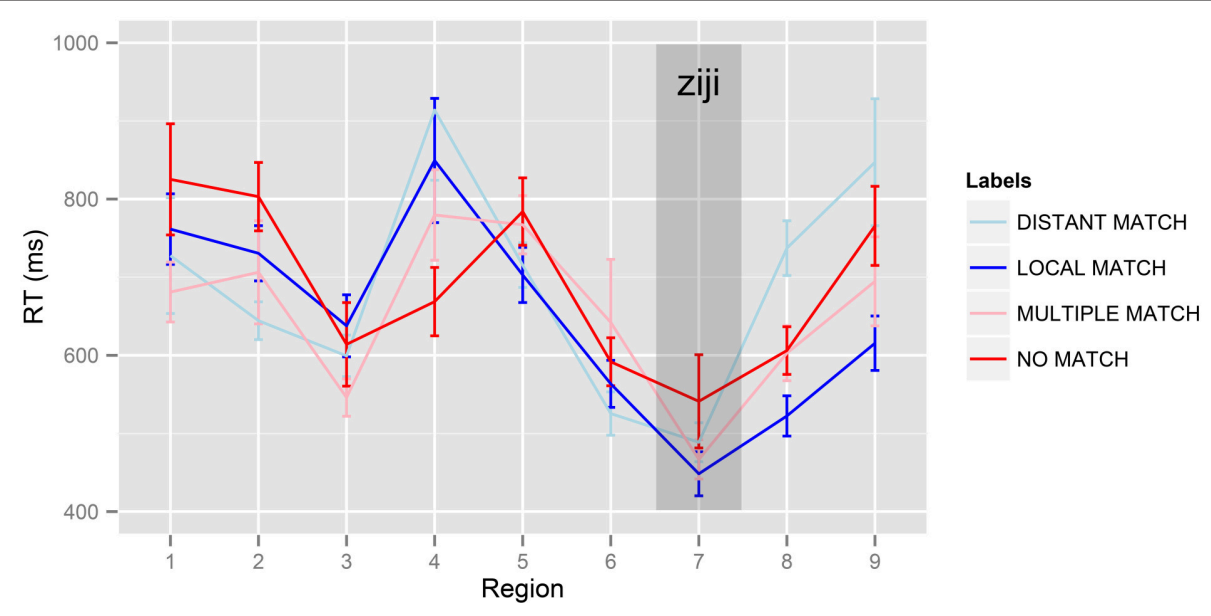

FIGURE 1 | Mean reading times per region in Experiment 1. Error bars represent standard error by participants, corrected for between-participant variance (Bakeman and McArthur, 1996). 1:Zhang taitai 2:jingchang guanggu de 3:na-ge 4:shizhuangdian 5:shang-ge-xingqi 6:ba 7:ta-ziji 8:bu xiaoxin 9:nongshang-le.

TABLE 3 | Mean acceptability ratings in Experiment 2.

\begin{tabular}{lccc}
\hline LOCAL MATCH & DISTANT MATCH & MULTIPLE MATCH & NO MATCH \\
$5.1(0.3)$ & $5(0.3)$ & $4.1(0.3)$ & $4(0.3)$ \\
\hline
\end{tabular}

Parentheses represent standard error by participants, corrected for between-participant variance (Bakeman and McArthur, 1996).

\section{Procedure}

The experimental procedure was identical to Experiment 1.

\section{Offline Judgments}

As in Experiment 1, we gathered offline naturalness judgments of all experimental materials prior to running Experiment 2. Collection of judgments and recruitment of participants proceeded in the same fashion as the offline pre-test for Experiment 1. Twenty-six native Mandarin speakers were recruited from Beijing Normal University.

The results of the offline judgment study are presented in Table 3. Linear mixed effects modeling revealed only an interaction of local and distant NP animacy (Est $=-1.88 \pm 0.38$, $t=-4.15)$. This interaction was driven by low ratings in the NO MATCH and MULTIPLE MATCH conditions. There was no appreciable difference between the ratings of the $L O C A L M A T C H$ and DISTANT MATCH conditions.

\section{Comprehension}

As in Experiment 1, one participant was removed from further analysis due to low accuracy (less than $70 \%$ accurate). Accuracy on the comprehension questions averaged $84 \%$ across participants, indicating that the participant attended to the stimuli. Across participants, accuracy ranged from 71 to $100 \%$.

\section{Reading Times}

Raw mean reading times are presented in Table 4 and Figure 2. Visual inspection of the means suggests a weaker locality effect in Experiment 2 than in Experiment 1: the difference between the LOCAL MATCH and DISTANT MATCH conditions was $57 \mathrm{~ms}$ at the critical region, and $53 \mathrm{~ms}$ at the spillover region (compared to $215 \mathrm{~ms}$ in Experiment 1). The reading times suggest a numerically an effect of the No Antecedent contrast (109 ms at the critical region, $148 \mathrm{~ms}$ in the spillover region), and a small effect for the Multiple Match contrast (10 ms at the critical region, $50 \mathrm{~ms}$ in the spillover region).

The results of the statistical modeling of the reaction times at the pre-critical, critical, and spillover regions are presented in Tables 5-7. Analysis revealed no significant effects of counterbalancing list, and so we report models that do not include list as a fixed effect predictor.

At the pre-critical region, $b a$, we did not observe any statistically significant effects. This pattern suggests any early differences in the materials between conditions-such as the 
TABLE 4 | Mean reading times per region in Experiment 2.

\begin{tabular}{|c|c|c|c|c|c|c|c|c|c|}
\hline & 1 & 2 & 3 & 4 & 5 & 6 & 7 & 8 & 9 \\
\hline LOCAL MATCH & $832(29)$ & 872 (33) & $643(25)$ & 818 (32) & 787 (32) & $584(23)$ & 590 (22) & 572 (22) & $670(43)$ \\
\hline DISTANT MATCH & $778(27)$ & 761 (22) & $698(46)$ & 785 (37) & $759(33)$ & $614(27)$ & $632(21)$ & $619(18)$ & $754(42)$ \\
\hline MULTIPLE MATCH & 765 (30) & 793 (30) & $634(20)$ & 824 (33) & $809(28)$ & $637(28)$ & $591(15)$ & $613(22)$ & $695(37)$ \\
\hline NO MATCH & 842 (32) & 904 (54) & 701 (31) & 765 (36) & $773(27)$ & $599(17)$ & $682(26)$ & $716(29)$ & $750(28)$ \\
\hline
\end{tabular}

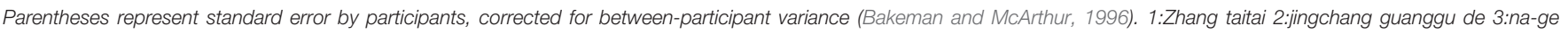
4:shizhuangdian 5:shang-ge-xingqi 6:ba 7:ta-ziji 8:bu xiaoxin 9:nongshang-le.

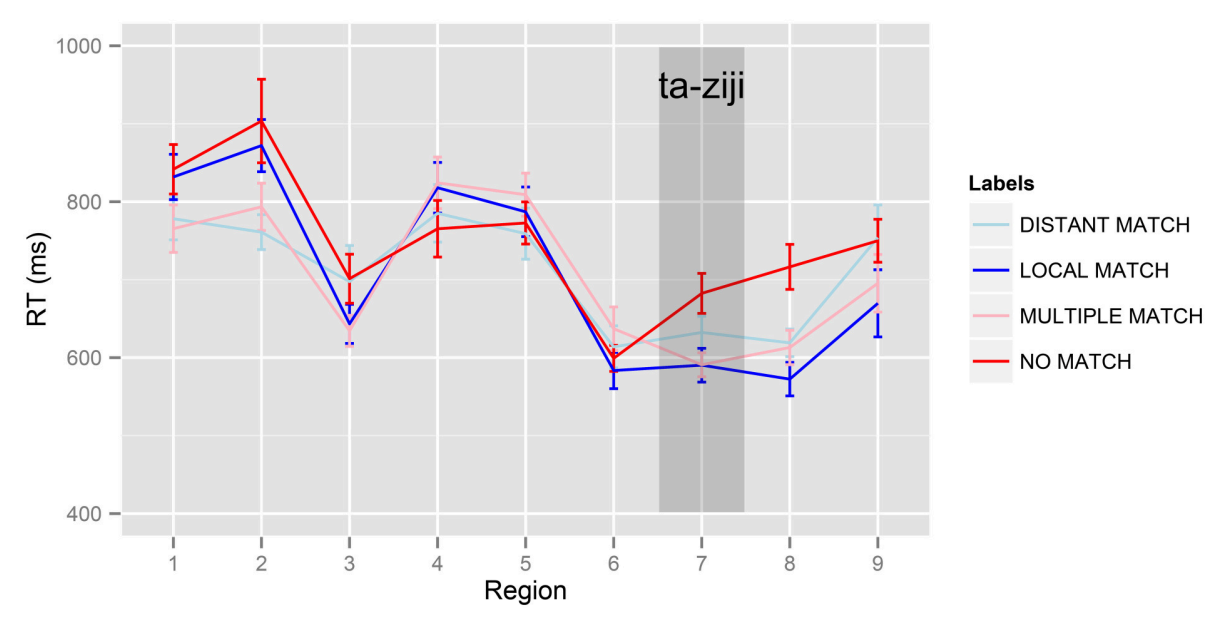

FIGURE 2 | Mean reading times per region in Experiment 2. Error bars represent standard error by participants, corrected for between-participant variance (Bakeman and McArthur, 1996). 1:Zhang taitai2:jingchang guanggu de 3:na-ge 4:shizhuangdian 5:shang-ge-xingqi 6:ba 7:ta-ziji 8:bu xiaoxin 9:nongshang-le.

TABLE 5 | Experimental fixed effects estimates from linear mixed effects modeling of pre-critical region across Experiments 1 and 2.

\begin{tabular}{lcr}
\hline & Estimate & \multicolumn{1}{c}{$\boldsymbol{t}$} \\
\hline Experiment & $0.09(0.06)$ & 1.45 \\
LOCALITY & $-0.02(0.05)$ & -0.40 \\
NO MATCH & $0.04(0.04)$ & 0.90 \\
MULTIPLE MATCH & $0(0.05)$ & 0.10 \\
Experiment: LOCALITY & $0.03(0.06)$ & 0.49 \\
Experiment: NO MATCH & $-0.01(0.06)$ & -0.17 \\
Experiment: MULTIPLEMATCH & $0.06(0.06)$ & 1.00 \\
\hline
\end{tabular}

animacy of the subject, or the different relative clauses used in different conditions-had returned to a neutral baseline prior to the critical region. We examined this observation further by performing an additional analysis of the region that immediately preceded the pre-critical region (e.g., shangge xingqi, "last week"). As in the pre-critical region, we failed to observe any statistically significant effects, providing further evidence that pre-critical differences in the materials across conditions did not have durable or long-lasting effects on reading times preceding the critical region.

In the critical region, we observed only a fixed effect of Experiment. Reading times in the anaphor region were
TABLE 6 | Experimental fixed effects estimates from linear mixed effects modeling of critical region across Experiments 1 and 2.

\begin{tabular}{lcr}
\hline & Estimate & $\boldsymbol{t}$ \\
\hline Experiment & $0.24(0.06)$ & 4.30 \\
LOCALITY & $0.06(0.05)$ & 1.26 \\
NO MATCH & $0.05(0.04)$ & 1.02 \\
MULTIPLE MATCH & $0(0.04)$ & 0.12 \\
Experiment: LOCALITY & $-0.02(0.05)$ & -0.38 \\
Experiment: NO MATCH & $0.05(0.05)$ & 0.91 \\
Experiment: MULTIPLEMATCH & $0.02(0.05)$ & 0.38 \\
\hline
\end{tabular}

significantly longer in Experiment 2 compared to Experiment 1, presumably reflecting the fact that ta-ziji is longer than $z i j i$.

In the spillover region, we observed a statistically significant effect of the Locality contrast, and a statistically significant effect of the No Antecedent contrast. We did not observe any significant effects of antecedent frequency or length. Critically, we observed an interaction of Experiment with the Locality contrast. The direction of this coefficient indicates that the locality contrast was significantly smaller in Experiment 2 than it was in Experiment 1. To further investigate the interaction of Experiment with the Locality contrast, we fit a second model in which the critical Locality contrast was nested within individual levels of 
TABLE 7 | Experimental fixed effects estimates from linear mixed effects modeling of spillover region across Experiments 1 and 2.

\begin{tabular}{lrr}
\hline & Estimate & \multicolumn{1}{c}{$\boldsymbol{t}$} \\
\hline Experiment & $0.13(0.06)$ & 2.03 \\
LOCALITY & $0.29(0.05)$ & 6.31 \\
NO MATCH & $0.14(0.04)$ & 3.05 \\
MULTIPLE MATCH & $0.05(0.05)$ & 1.08 \\
Experiment: LOCALITY & $-0.22(0.06)$ & -3.94 \\
Experiment: NO MATCH & $0.03(0.06)$ & 0.52 \\
Experiment: MULTIPLEMATCH & $0.01(0.05)$ & 0.14 \\
\hline
\end{tabular}

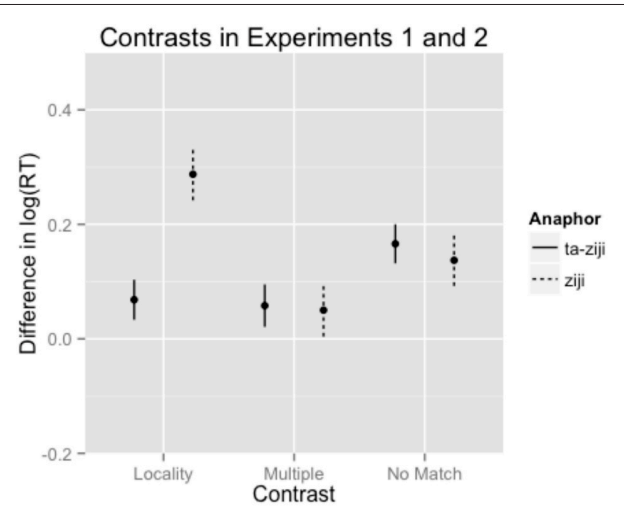

FIGURE 3 | Fixed effects estimates for Experimental contrasts in the spill-over region in both Experiment 1 (ziji) and Experiment 2 (ta-ziji). Error bars indicate the standard error associated with the fixed effect estimate.

Experiment. This model revealed that there was a significant Locality contrast for Experiment 1 (0.29 (0.05), $t=6.31)$. In Experiment 2, the estimated size of this effect was much smaller than in Experiment 1, and it was only marginal for Experiment 2 (0.07 (0.04), $t=1.95)$. The magnitude of the No Antecedent contrast was comparable between Experiments 1 and 2, and it reached statistical significance in both Experiments [Experiment 1: 0.14 (0.04), $t=3.05$; Experiment 2: $0.17(0.03), t=4.85]$. The Multiple Match contrast did not reach significance in either Experiment, although the magnitude of the observed effect and its sign were comparable across experiments [Experiment 1: 0.05 $(0.05), t=1.08$; Experiment 2: $0.06(0.04), t=1.56]$. The estimates of the fixed effects contrasts by Experiment yielded by this model are presented in Figure 3.

\section{Discussion}

The offline judgments for sentences containing ta-ziji revealed that the DISTANT MATCH and LOCAL MATCH conditions were considered equally acceptable, and that both were considered more acceptable than the NO MATCH condition. This pattern confirms that the distant subject position is accessible as an antecedent for ta-ziji in our materials. Furthermore, this pattern gives no indication of a locality bias in the offline judgments for $t a-z i j i$. This contrasts sharply with the clear offline locality bias observed for ziji in Experiment 1.
Note furthermore that our DISTANT MATCH and LOCAL $M A T C H$ conditions differed in whether the main clause subject was animate. As the DISTANT MATCH condition was rated equally highly as the LOCAL MATCH condition in this experiment, one may infer that the inanimate main clause subjects in the DISTANT MATCH condition did not impact the naturalness of the sentences. This further suggests that the difference we observed between DISTANT MATCH and LOCAL $M A T C H$ in the judgments and reading times in Experiment 1 reflect aspects of the processing of $z i j i$, rather than unacceptability that results from the presence of inanimate main clause subjects in the DISTANT MATCH condition.

Turning to the reading times, statistical modeling of the results yields several important insights. First, although both the Locality contrast was significant at the spillover region for both $z i j i$ and $t a-z i j i$, there was a significant interaction of Locality and Experiment: the magnitude of the locality effect was much smaller for ta-ziji than for ziji. Although the locality effect was several times smaller for ta-ziji than for ziji, post-hoc analysis revealed that the Locality contrast was significant for both anaphors.

However, apart from this crucial difference, the processing of both anaphors was qualitatively similar. Our analysis revealed a significant No Antecedent contrast that did not differ in magnitude across studies. This indicates that comprehenders did indeed try to assign a referent to the anaphor upon encountering it, and moreover, it suggests that comprehenders experienced a similar amount of processing difficulty when there was no sentence-internal antecedent for both $z i j i$ and ta-ziji. Likewise, the magnitude of the Multiple Match contrast was similar across the two experiments, although it failed to reach statistical significance either in the omnibus analysis, or in the post-hoc analyses by experiment.

\section{GENERAL DISCUSSION}

In two self-paced reading experiments, we investigated the processing of two reflexive anaphors in Mandarin: the bare monomorphemic reflexive $z i j i$, and the morphologically complex reflexive ta-ziji. In both offline acceptability rating and online reading time results, we observed that $z i j i$ was associated with a robust locality bias. Non-local interpretation of ziji was associated with lower naturalness ratings and longer reading times. In contrast, we observed a significantly smaller locality effect for ta-ziji in reading times, and no locality effect in offline acceptability judgments. Interestingly, this was the only difference we observed between ziji and ta-ziji. For both anaphors, we observed reliable reading time slowdowns when there was no licit antecedent in the sentence, and the size of this no match penalty did not reliably differ between anaphors in reading time measures. Likewise, for both anaphors we observed a trend toward a multiple match penalty. This effect did not reach statistical significance, although the consistency of the effect in sign and magnitude across experiments raises the possibility that the failure to observe this effect reflects a lack of statistical power. We take up each of these effects in turn. 


\section{Feature Richness and Antecedent Search}

Our findings suggest that the locality bias that is associated with ziji does not generalize to other Mandarin reflexives that can take antecedents outside of their immediate tensed clause. Specifically, the morphologically complex anaphor ta-ziji shows a much diminished locality bias in online processing measures. One plausible hypothesis about this difference is that the overt morphological feature content on ta-ziji leads to faster or more reliable access to structurally distant antecedents. In contrast, $z i j i$ has fewer overt morphological cues to its antecedent, and so comprehenders may need to rely more heavily on positional cues to isolate its antecedent in memory, leading to relatively more pronounced locality bias.

This hypothesis is plausible given existing theories of how comprehenders access information in working memory during sentence comprehension. For a wide range of linguistic dependencies, there is evidence that the processor makes use of a content-addressable retrieval mechanism to form syntactic and referential dependencies between temporally distant phrases (McElree, 2000, 2006, 2014; McElree et al., 2003; Lewis and Vasishth, 2005; Lewis et al., 2006; McElree, 2006; Van Dyke and McElree, 2006, 2011; Foraker and McElree, 2011). A contentaddressable retrieval mechanism accesses a representation in memory using the inherent features of the representation as cues to guide memory retrieval process. For example, a pronoun like him may be said to retrieve its antecedent by using gender features as cues to locate an antecedent in memory (e.g., Foraker and McElree, 2007). These cues are said to provide direct access to the desired representation, obviating any need to search through irrelevant representations at retrieval. This mechanism has the benefit of granting extremely rapid access to information in memory, making this an attractive mechanism for memory access in the human sentence processor (Lewis et al., 2006). In general, models that posit a content-addressable retrieval mechanism predict that an increase in structural or linear distance between the retrieval site (e.g., the anaphor) and the target of retrieval (e.g., its antecedent) may lead to reduced retrieval accuracy, but that structural or linear distance per se should not result in longer retrieval times. On some theoretical proposals, the speed of retrieval may be modulated by variables such as retrieval interference and temporal decay (Lewis and Vasishth, 2005; Lewis et al., 2006); on others, these variables primarily impact the probability of successfully recovering a target representation (McElree, 2006). Although cue-based models have the advantage of offering rapid access to representations in memory when they are required for sentence comprehension, they encounter difficulty if multiple representations in memory match the retrieval cues used at retrieval. If this occurs, it may be more difficult to isolate the target representation in memory, a phenomenon known as retrieval interference. Retrieval interference has been shown to be a primary cause of difficulty in sentence comprehension (Lewis, 1996; Van Dyke and Lewis, 2003; Lewis and Vasishth, 2005; Lewis et al., 2006; Van Dyke and McElree, 2006; Van Dyke, 2007; see also Gordon et al., 2001, 2002, 2004; for a recent review, see Van Dyke and Johns, 2012).
Several distinct hypotheses that draw upon this basic framework have been proposed to explain the locality bias associated with ziji. Chen et al. (2012) and Jäger et al. (2015) offered an account that draws on the ACT-R model of Lewis and Vasishth (2005). This model explains the locality bias as the result of decay and interference reducing the activation level of the distant subject, which in turn leads to longer antecedent retrieval times when the antecedent is distant from the anaphor. An alternative explanation is offered by Dillon et al. (2014), who proposed that the locality effect arises because comprehenders tend to initially retrieve the local subject as an antecedent for $z i j i$. On this view, comprehenders must reject the local subject as a plausible antecedent and execute additional memory retrievals to access a distant antecedent for ziji. On this view, more retrieval operations are necessary to access distant antecedents, and so it is predicted that processing times should increase whenever ziji needs to take an antecedent other than the most local one.

One finding that distinguishes these two accounts is the MR-SAT study reported by Dillon et al. (2014). Dillon and colleagues observed that ziji with distant antecedents led to significantly slower processing rates in the speed-accuracy tradeoff function than ziji with local antecedents. Standard memory variables such as temporal decay and interference alone have not been shown to modulate processing speed in the speed-accuracy tradeoff functions associated with linguistic processing (McElree, 2000; McElree et al., 2003; Foraker and McElree, 2007, 2011; Martin and McElree, 2008, 2009, 2011; Van Dyke and McElree, 2011). However, processing speed as measured in the speed-accuracy tradeoff function has been shown to be slowed down by increasing the number of required retrieval operations, and in situations where syntactic reanalysis is required (McElree et al., 2003; Bornkessel et al., 2004; Foraker and McElree, 2007). Thus, the MR-SAT data lend support to the view that the locality effect arises because comprehenders are tempted to initially retrieve and evaluate the local subject as an antecedent when processing ziji.

This account also offers some insight into how the overt feature content of ta-ziji may allow comprehenders to overcome locality bias in comprehension. Many different implementations of cue-based retrieval mechanisms predict that the more highly specified a retrieval probe is in terms of the cues used, the less likely it is that partially matching (distractor) items in memory will cause retrieval interference, and compete with other representations at retrieval (Lewis and Vasishth, 2005; Van Dyke and McElree, 2006; Van Dyke, 2007). These models hold that retrieval probes that contain a greater number of retrieval cues will see a corresponding increase in the probability of recovering a target item in memory, because more numerous and specific retrieval cues will in general decrease the probability of retrieving a distractor that only matches a subset of the retrieval cues.

To illustrate how these models would account for the difference in the magnitude of the locality effect for $z i j i$ and $t a-z i j i$, consider again the critical configuration in (9): 


\section{(9) 张太太 经常 光顾 的那个时装店}

Zhang taitai $i_{i}$ jingchang guanggu de na-ge shizhuangdian $_{j}$ 上个星期把自己 不小心 弄伤了

shang-ge-xingqi ba $\mathrm{ziji}_{i} * *_{j}$ bu xiaoxin nongshang-le.

Mrs. Zhang often visit DE that-CL boutique last-week BA self not careful harm-PERF.

"The boutique that Mrs. Zhang often visits carelessly harmed her last week."

Upon reaching the anaphor, comprehenders will, by hypothesis, recruit a mixture of syntactic cues (e.g., cues to subjecthood, such as syntactic case) and semantic or morphological cues (e.g., animacy in the case of ziji; animacy, humanness, and perhaps gender in the case of $t a-z i j i)$. Although these cues form a perfect match to the target antecedent, the inappropriate local subject shizhuangdian (boutique) matches only the syntactic cues. Thus, it is possible for the local antecedent to be mis-retrieved some proportion of the time, because it partially matches the syntactic cue content of the retrieval probe. Although we might reasonably expect the semantically appropriate long-distance antecedent to outcompete the local subject at retrieval in many cases, the competition contributed by the local subject may be exacerbated by its recency or its structural proximity to the anaphor (Dillon et al., 2014). If the retrieval probe contains relatively few semantic cues, the likelihood of mis-retrieving the local subject may be relatively high. On the account offered by Dillon et al. (2014), this is precisely what happens when comprehenders process ziji: although ziji contains animacy cues, these are not enough to overcome interference from the local subject, and so the local subject is retrieved some proportion of the time. When this occurs, comprehenders must attempt additional retrievals in order to arrive at an acceptable interpretation of the anaphor.

In the case of ta-ziji, the addition of humanness and gender features into the retrieval probe ensures that the local subject na-ge shizhuangdian "that boutique" matches fewer retrieval cues in the probe. This decreases the probability of retrieving the partially matching local subject, resulting in a greater proportion of trials when comprehenders are able to access the desired antecedent without sampling multiple antecedent representations from memory. Thus, if the locality bias reflects a tendency to mis-retrieve and consider the local subject, rather than decay of the distant antecedent per se, then the locality bias is predicted to be smaller for $t a-z i j i$ than for $z i j i$. Put simply, ta-zijis additional feature content decreases the attractiveness of the local subject as a distractor and makes it more likely that comprehenders will successfully retrieve the long-distance antecedent on their first attempt.

Although, we have offered an explanation of our results in terms of the likelihood that the local subject will be (mis)retrieved when processing the anaphor, it remains to be seen whether accounts that explain the locality bias effect as decreased activation of the distant antecedent can account for the difference between $z i j i$ and $t a-z i j i$. The contrast between these anaphors rules out the simple hypothesis that the locality bias associated with $z i j i$ is due to recency or temporal decay alone. This is because this hypothesis would predict an equal locality effect for both anaphors. However, it may be possible to capture the present finding in more sophisticated models where the activation of an item in memory is partially a function of the retrieval cues used to access memory, such as the ACT-R model of Lewis and Vasishth (2005). It is difficult to evaluate the predictions of these models without the aid of an implemented computational model. The predictions of this account vary substantially with specific modeling assumptions that one makes. For example, if one assumes that the distant antecedent in examples like (9) is a perfect match to the retrieval probe of $z i j i$ and ta-ziji alike, then the activation of the distant antecedent should not be modulated by the number of retrieval cues in the retrieval probe ${ }^{1}$. This is because the total activation boost that a retrieval probe gives to an item in memory is constant in ACT-R. Adding more retrieval cues to the probe therefore does not increase the amount of activation afforded to a perfectly matching item in memory; it instead diminishes the amount of activation boost that is contributed by any one cue on its own. Under these conditions, availability of the distant antecedent is not predicted to differ between $z i j i$ and $t a-z i j i$, all else being equal. However, if one relaxes these assumptions, it may be possible to capture this result. Thus, although we cannot claim that the present results are incompatible with the explanation of the locality bias effect offered by Chen et al. (2012) and Jäger et al. (2015), more research and modeling work is necessary to determine the specific circumstances under which these models can capture the contrast between ziji and ta-ziji.

\section{Ziji vs. Ta-ziji}

The explanation we offer for our findings posits that overt morphological features provide retrieval cues for recovering an antecedent for an anaphoric expression. However, the precise relationship between overt morphological form and the cues used to retrieve an antecedent remains unclear. Indeed, the problem of specifying the nature of the retrieval cues that support language processing is a key theoretical issue for cue-based approaches, and remains an area where much further work is needed (Van Dyke and McElree, 2011; Dillon et al., 2013). Previous research suggests that the link between overt morphological feature content and retrieval cues may be rather indirect, such that there is not a one-to-one mapping between overt morphological features and retrieval cues. For example, Dillon et al. (2013) presented a series of studies that investigated the processing of English reflexive himself. On the basis of a comparison between computational retrieval models and online reading time data, they suggest that himself does not use gender and number features as cues to retrieve its antecedent, instead relying on a mixture of structural and locality cues (Dillon et al., 2013; Dillon, 2014; but see Jäger et al., 2015, for a critical view of this conclusion and an alternative analysis of these findings). Put differently, Dillon et al. (2013) proposed that the morphologically complex English reflexive himself deploys a cue set that is fundamentally similar to the cue set proposed for Mandarin ziji, despite the fact

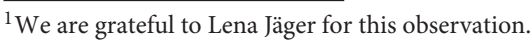


that himself is morphologically more similar to Mandarin ta-ziji than it is to ziji. This contrast suggests that the simple hypothesis that overt morphological features are recruited as retrieval cues may not be correct, but we presently lack a theory of how morphological and semantic features of anaphoric expressions are used during antecedent retrieval.

Resolving this tension is beyond the scope of this paper, but there are several possibilities that suggest themselves. It may be that the direct link between morphology and retrieval cues that we offer as an explanation for the present findings is misguided, and some other difference between ziji and ta-ziji is responsible for the difference in their processing behavior. One plausible alternative explanation of our result could leverage the observation that $t a-z i j i$ may be readily interpreted as a contrastive reflexive, analogous to he himself in English (Pan, 1998; what Baker, 1995 calls an intensive pronoun). Baker (1995) suggests that the interpretive constraints on these intensive pronouns are best understood in terms of discourse prominence and contrastiveness of potential antecedents, rather than their syntactic positions. It is possible that the diminished locality effect for ta-ziji reflects a preference to construe ta-ziji as an intensive pronoun in our experiment. This could have caused readers to weight discourse cues more heavily than syntactic cues when retrieving an antecedent for ta-ziji, leading to a smaller locality effect. While we find this an interesting possibility, we cannot confidently endorse it on the basis of the present data because it is at present unclear whether readers understood ta-ziji as an anaphor or an intensive pronoun in our experiment. Another possibility is that the difference in locality bias reflects a difference in the frequency with which each anaphor takes antecedents beyond its local clause. Although we cannot rule out this possibility, we find it unlikely: the number of syntactic environments where ta-ziji can find an antecedent outside of its tensed clause is much smaller than the number of environments where ziji can, making it unlikely that $z i j i$ more often takes a local antecedent than ta-ziji in a Mandarin speaker's language experience. Nonetheless, corpus work would be necessary to secure this conclusion, and at present we must regard it as a possible, but unlikely, explanation of the present finding.

\section{Multiple Match Effects}

A further prediction of cue-based retrieval models is that the presence of multiple antecedents that match the retrieval cues of the anaphor should create retrieval interference, which should in turn create processing difficulty. For example, consider our MULTIPLE MATCH condition:

\section{(10) 张太太 经常 光顾 的那个女裁缝}

Zhang taitai ${ }_{i}$ jingchang guanggu de na-ge nücaifeng; $_{j}$

上个星期 把自己不小心 弄伤了

shang-ge-xingqi ba ziji $*_{i} / \mathrm{j}$ buxiaoxin nongshang-le.

Mrs. Zhang often visit DE that-CL seamstress last-week ba self not careful harm-PERF.

"The seamstress that Mrs. Zhang often visits carelessly harmed her last week."
This sentence is not ambiguous, as the animate head noun nücaifeng ("seamstress") blocks access to the embedded subject Zhang taitai ("Mrs. Zhang"; see Tang, 1989). In other words, Zhang taitai is a grammatically inaccessible distractor in this example, even though this syntactic position would have been grammatically accessible if the relative clause's head noun were inanimate. Nonetheless, because the distant subject Zhang taitai matches the retrieval cues of the anaphor, it is predicted to create retrieval interference. Because there are multiple antecedents that match the animacy cues associated with $z i j i$, it should be more difficult for comprehenders to isolate the correct antecedent nücaifeng in memory. In terms of our experimental manipulations, cue-based parsing models broadly predict that the MULTIPLE MATCH condition should be more difficult than the LOCAL MATCH condition at the reflexive, because the MULTIPLE MATCH condition contains more representations that match the retrieval cues, contributing to retrieval interference in the MULTIPLE MATCH condition that should inhibit access to the target antecedent. Moreover, it is predicted that the size of the multiple match effect should be greater for $t a-z i j i$ than for $z i j i$, because the distractor matches a greater proportion of the retrieval cues for the complex anaphor.

Our experiments failed to provide clear evidence to support or disconfirm these predictions. In both Experiments 1 and 2, we observed numerically longer reading times on the MULTIPLE MATCH condition than in the LOCAL MATCH condition, but this contrast did not reach statistical significance in either experiment alone, and we failed to observe any trend toward a larger multiple match effect for ta-ziji. The interpretation of the present findings, and their relationship with previous findings, must therefore be treated with caution. We note that the size and magnitude of the multiple match effect was consistent, and in the predicted direction, in both experiments. This pattern suggests that our failure to find an effect may reflect a lack of statistical power.

Although a multiple match penalty has been observed in previous reading time studies (Badecker and Straub, 1994, 2002; Kennison et al., 2003; Felser et al., 2009; Chen et al., 2012; Jäger et al., 2015; see also Rigalleau et al., 2004; Stewart et al., 2007), the empirical generalization has remained unclear, especially for reflexive pronouns. Although some studies have presented evidence that feature-matched, but structurally inaccessible antecedents create processing difficulty for reflexive pronouns (Badecker and Straub, 2002; Felser et al., 2009; Chen et al., 2012; Jäger et al., 2015), many more studies have failed to find reliable evidence for such an effect in reading time measures, or found it only in limited contexts (Clifton et al., 1999; Sturt, 2003; Xiang et al., 2009; Cunnings and Felser, 2013; Dillon et al., 2013; Cunnings and Sturt, 2014; Kush and Phillips, 2014; Jäger et al., 2015). It is notable that Chen and colleagues reported that reading times on ziji were longer in the presence of a grammatically inaccessible, but semantically appropriate antecedent (c.f., Jäger et al., 2015). On balance, however, the repeated failures to find multiple match effects suggest that grammatically illicit antecedents do not create substantial interference effects, and so our failure to find 
any multiple match effects in the present study may not be surprising. Dillon (2014) and Sturt (2013) offer reviews of the empirical landscape, and suggest that grammatical constraints act as strong filters on antecedent retrieval, allowing for very little (if any) retrieval interference from grammatically illicit antecedents.

A similar pattern emerges for studies that have focused on the processing of direct object pronouns in English. Chow et al. (2014) reported five experiments that sought to find multiple match effects with direct object pronouns in English, and failed to find any evidence of such an effect (including a near direct replication of Badecker and Straub, 2002). On the basis of this finding, Chow and colleagues argued that, in line with the processing of reflexives, structural constraints acted immediately to help rule out grammatically inaccessible antecedents for object pronouns as well (see also Clifton et al., 1997; Lee and Williams, 2008; Patterson et al., 2014).

On the basis of the non-significant multiple match effects in the present studies, very little can be concluded about whether the inaccessible antecedent in our MULTIPLE MATCH conditions created retrieval interference. However, inconsistent with claims that grammatical constraints rule out inaccessible antecedents, we did find clear trends in the predicted direction in both experiments. We thus regard it as an open empirical question whether an animate distant subject interferes with the retrieval of the correct local subject when processing ziji and ta-ziji.

\section{REFERENCES}

Badecker, W., and Straub, K. (1994). "Evidence that binding principles participate in a constraint satisfaction process," in Poster Presented at the 7th CUNY Sentence Processing Conference (New York, NY).

Badecker, W., and Straub, K. (2002). The processing role of structural constraints on interpretation of pronouns and anaphors. J. Exp. Psychol. Learn. Mem. Cogn. 28, 748. doi: 10.1037/0278-7393.28.4.748

Bakeman, R., and McArthur, D. (1996). Picturing repeated measures: comments on Loftus, Morrison, and others. Behav. Res. Methods Instrum. Comput. 28, 584-589. doi: 10.3758/BF03200546

Baker, C. L. (1995). Contrast, discourse prominence, and intensification, with special reference to locally free reflexives in British English. Language 71, 63-101. doi: 10.2307/415963

Barr, D. J., Levy, R., Scheepers, C., and Tily, H. J. (2013). Random effects structure for confirmatory hypothesis testing: keep it maximal. J. Mem. Lang. 68, 255-278. doi: 10.1016/j.jml.2012.11.001

Bornkessel, I., McElree, B., Schlesewsky, M., and Friederici, A. D. (2004). Multi-dimensional contributions to garden path strength: dissociating phrase structure from case marking. J. Mem. Lang. 51, 495-522. doi: 10.1016/j.jml.2004.06.011

Box, G. E., and Cox, D. R. (1964). An analysis of transformations. J. R. Stat. Soc. B 26, 211-252.

Büring, D. (2005). Binding Theory. Cambridge: Cambridge University Press.

Cai, Q., and Brysbaert, M. (2010). SUBTLEX-CH: Chinese word and character frequencies based on film subtitles. PLOS ONE 5:e10729. doi: 10.1371/journal.pone.0010729

Chen, Z., Jäger, L., and Vasishth, S. (2012). How structure-sensitive is the parser? Evidence from Mandarin Chinese. Emp. Approaches Linguist. Theory111:43. doi: $10.1515 / 9781614510888.43$

\section{CONCLUSION}

In our Experiment 1, we observed that the morphologically simple long-distance reflexive ziji showed a robust locality bias in reading time measures. Experiment 2 revealed that the morphologically complex, local reflexive ta-ziji showed a much reduced locality bias in processing. We proposed that this contrast was due to the number of morphological and semantic features each anaphor uses during the process of retrieving an antecedent. Morphologically simple anaphors like $z i j i$, which have relatively fewer retrieval cues, are more likely to access non-target antecedents at retrieval. This requires comprehenders to sample multiple antecedents in order to achieve an interpretation for the anaphor, leading to locality effects. In contrast, the relatively more specified ta-ziji has more cues for antecedent retrieval, which makes it less susceptible to interference from non-target representations. For this reason, complex anaphors like ta-ziji show diminished locality effects in comprehension.

\section{ACKNOWLEDGMENTS}

We would like to thank Lyn Frazier, Lena Jäger, and Dave Kush for comments on and discussion of an earlier version of this work, and Colin Phillips for extended discussion of the experiments presented here. This work was supported by a University of Maryland Fellowship to BD and WC. Experiments 1 and 2 were initially presented as part of Dillon (2011).
Chomsky, N. (1981). Lectures on Government and Binding. Dordrecht: Foris.

Chow, W. Y., Lewis, S., and Phillips, C. (2014). Immediate sensitivity to structural constraints in pronoun resolution. Front. Psychol. 5:630. doi: 10.3389/fpsyg.2014.00630

Clifton, C., Frazier, L., and Deevy, P. (1999). Feature manipulation in sentence comprehension. Riv. Lingüíst. 11, 11-40.

Clifton, C., Kennison, S. M., and Albrecht, J. E. (1997). Reading the wordsher, his, him: implications for parsing principles based on frequency and on structure. J. Mem. Lang. 36, 276-292. doi: 10.1006/jmla.1996.2499

Cunnings, I., and Felser, C. (2013). The role of working memory in the processing of reflexives. Lang. Cogn. Process. 28, 188-219. doi: $10.1080 / 01690965.2010 .548391$

Cunnings, I., and Sturt, P. (2014). Coargumenthood and the processing of reflexives. J. Mem. Lang. 75, 117-139. doi: 10.1016/j.jml.2014.05.006

Dillon, B. (2011). Structured Access in Sentence Comprehension. Unpublished Ph.D. dissertation, University of Maryland.

Dillon, B. (2014). Syntactic memory in the comprehension of reflexive dependencies: an overview. Lang. Linguist. Compass 8, 171-187. doi: $10.1111 /$ lnc3.12075

Dillon, B., Chow, W. Y., Wagers, M., Guo, T., Liu, F., and Phillips, C. (2014). The structure-sensitivity of memory access: evidence from Mandarin Chinese. Front. Psychol. 5:1025. doi: 10.3389/fpsyg.2014.01025

Dillon, B., Mishler, A., Sloggett, S., and Phillips, C. (2013). Contrasting intrusion profiles for agreement and anaphora: experimental and modeling evidence. J. Mem. Lang. 69, 85-103. doi: 10.1016/j.jml.2013. 04.003

Drummond, A. (2011). IbexFarm (Version 0.2.7) [Software]. Available online at: http://spellout.net/ibexfarm/

Elbourne, P. D. (2008). The interpretation of pronouns. Lang. Linguist. Compass 2, 119-150. doi: 10.1111/j.1749-818X.2007.00041.x 
Felser, C., Sato, M., and Bertenshaw, N. (2009). The on-line application of binding Principle $\mathrm{A}$ in English as a second language. Bilingualism Lang. Cogn. 12, 485-502. doi: 10.1017/S1366728909990228

Foraker, S., and McElree, B. (2007). The role of prominence in pronoun resolution: availability versus accessibility. J. Mem. Lang. 56, 357-383. doi: 10.1016/j.jml.2006.07.004

Foraker, S., and McElree, B. (2011). Comprehension of linguistic dependencies: speed-accuracy tradeoff evidence for direct-access retrieval from memory. Lang. Linguist. Compass 5, 764-783. doi: 10.1111/j.1749-818X.2011.00313.x

Gao, L., Liu, Z., and Huang, Y. (2005). Who is ziji? An experimental research on Binding Principle. Linguist. Sci. 2, 39-50.

Gernsbacher, M. A. (1989). Mechanisms that improve referential access. Cognition 32, 99-156. doi: 10.1016/0010-0277(89)90001-2

Gordon, P. C., Hendrick, R., and Johnson, M. (2001). Memory interference during sentence processing. Psychol. Sci. 13, 425-430. doi: 10.1111/1467-9280.00475

Gordon, P. C., Hendrick, R., and Johnson, M. (2004). Effects of noun phrase type on sentence complexity. J. Mem. Lang. 51, 97-114. doi: 10.1016/j.jml.2004.02.003

Gordon, P. C., Hendrick, R., and Levine, W. H. (2002). Memory-load interference in syntactic processing. Psychol. Sci. 13, 425-430. doi: 10.1111/1467-9280.00475

Greene, S. B., McKoon, G., and Ratcliff, R. (1992). Pronoun resolution and discourse models. J. Exp. Psychol. Learn. Mem. Cogn. 18:266. doi: 10.1037/02787393.18.2.266

Heim, I. (1982). The Semantics of Definite and Indefinite Noun Phrases. Ph.D. dissertation, University of Massachusetts, Amherst.

Huang, C.-T. J., Cole, P., and Hermon, G. (2006). "Long-distance reflexives: an East Asian perspective," in The Blackwell Companion to Syntax, Volu. III, eds M. Everaert, H. van Riemsdijk, R. Goedemans, and B Hollebrandse (Location: Blackwell), 21-84.

Huang, C.-T. J., and Liu, L. (2001). "Logophoricity, attitudes, and ziji at the interface," in in Long Distance Reflexives, Syntax and Semantics 33, eds P. Cole, C.-T. J. Huang, and G. Hermon (New York, NY: Academic Press), 141-195.

Huang, C.-T. J., Li, Y.-H. A., and Li, Y. (2009). The Syntax of Chinese. Cambridge, UK: Cambridge University Press.

Huang, C. T. J., and Tang, C. C. J. (1991). "The local nature of the longdistance reflexive in Chinese," in Long Distance Anaphora, eds J. Koster and E. Reuland (Cambridge: Cambridge University Press), 263-283. doi: 10.1017/CBO9780511627835.014

Jäger, L. A., Engelmann, F., and Vasishth, S. (2015). Retrieval interference in reflexive processing: experimental evidence from Mandarin, and computational modeling. Front. Psychol. 6:617. doi: 10.3389/fpsyg.2015. 00617

Kennison, S. M. (2003). Comprehending the pronouns her, him, and his: implications for theories of referential processing. J. Mem. Lang. 49, 335-352. doi: 10.1016/S0749-596X(03)00071-8

Kintsch, W. (1975). Memory Representations of Text. Information Processing and Cognition. Hillsdale, NJ: Erlbaum.

Kush, D. (2013). Respecting Relations: Memory Access and Antecedent Retrieval in Incremental Sentence Processing. Unpublished doctoral dissertation, University of Maryland, College Park.

Kush, D., and Phillips, C. (2014). Local anaphor licensing in an SOV language: implications for retrieval strategies. Front. Psychol. 5:1252. doi: 10.3389/fpsyg.2014.01252

Lee, M. W., and Williams, J. N. (2008). The Role of Grammatical Constraints in Intra-Sentential Pronoun Resolution. London: London Metropolitan University/Cambridge University manuscript.

Lewis, R., and Vasishth, S. (2005). An activation-based model of sentence processing as skilled memory retrieval. Cogn. Sci. 29, 375-419. doi: 10.1207/s15516709cog0000_25

Lewis, R., Vasishth, S., and Van Dyke, J. (2006). Computational principles of working memory in sentence comprehension. Trends Cogn. Sci. 10, 447-454. doi: 10.1016/j.tics.2006.08.007

Lewis, R. L. (1996). Interference in short-term memory: the magical number two (or three) in sentence processing. J. Psycholinguist. Res. 25, 93-115. doi: $10.1007 / \mathrm{BF} 01708421$

Li, X., and Zhou, X. (2010). Who is ziji? ERP responses to the Chinese reflexive pronouns during sentence comprehension. Brain Res. 1331, 96-104. doi: 10.1016/j.brainres.2010.03.050
Liu, Z. (2009). The cognitive process of Chinese reflexive processing. J. Chinese Linguist. 37, 1-27.

Martin, A. E., and McElree, B. (2008). A content-addressable pointer mechanism underlies comprehension of verb-phrase ellipsis. J. Mem. Lang. 58, 879-906. doi: 10.1016/j.jml.2007.06.010

Martin, A. E., and McElree, B. (2009). Memory operations that support language comprehension: evidence from verb-phrase ellipsis. J. Exp. Psychol. Learn. Mem. Cogn. 35, 1231-1239. doi: 10.1037/ a0016271

Martin, A. E., and McElree, B. (2011). Direct-access retrieval during sentence comprehension: evidence from Sluicing. J. Mem. Lang. 64, 327-343. doi: 10.1016/j.jml.2010.12.006

McElree, B. (2000). Sentence comprehension is mediated by contentaddressable memory structures. J. Psycholinguist. Res. 29, 111-123. doi: 10.1023/A:1005184709695

McElree, B. (2006). Accessing recent events. Psychol. Learn. Mot. 46, 155-200. doi: 10.1016/S0079-7421(06)46005-9

McElree, B. (2014). "Memory processes underlying real-time language comprehension," in Remembering: Attributions, Processes, and Control in Human Memory, eds D. S. Lindsay, C. M. Kelley, A. P. Yonelinas and H. L. Roediger (New York, NY: Psychology Press), 133-151.

McElree, B., Foraker, S., and Dyer, L. (2003). Memory structures that subserve sentence comprehension. J. Mem. Lang. 48, 67-91. doi: 10.1016/S0749596X(02)00515-6

Myers, J. L., and O’Brien, E. J. (1998). Accessing the discourse representation during reading. Discourse Process. 26, 131-157. doi: $10.1080 / 01638539809545042$

Pan, H. (1998). Closeness, prominence, and binding theory. Nat. Lang. Linguist. Theory 16, 771-815. doi: 10.1023/A:1006056414208

Pan, H. (2000). Why the blocking effect. Syntax Semant. 33, 279-316. doi: 10.1108/S0092-4563(2000)0000033011

Patterson, C., Trompelt, H., and Felser, C. (2014). The online application of binding condition $\mathrm{B}$ in native and non-native pronoun resolution. Front. Psychol. 5:147. doi: 10.3389/fpsyg.2014.00147

Rigalleau, F., Caplan, D., and Baudiffier, V. (2004). New arguments in favour of an automatic gender pronominal process. Q. J. Exp. Psychol. A, 57, 893-933. doi: $10.1080 / 02724980343000549$

Rohde, D. (2003). Linger (Version 2.94) [Software]. Available online at: http://tedlab.mit.edu/ dr/Linger/

Sprouse, J., Fukuda, S., Ono, H., and Kluender, R. (2011). Reverse island effects and the backward search for a licensor in multiple wh-questions. Syntax 14, 179-203. doi: 10.1111/j.1467-9612.2011.00153.x

Stewart, A. J., Holler, J., and Kidd, E. (2007). Shallow processing of ambiguous pronouns: evidence for delay. Q. J. Exp. Psychol. 60, 1680-1696. doi: $10.1080 / 17470210601160807$

Sturt, P. (2003). The time-course of the application of binding constraints in reference resolution. J. Mem. Lang. 48, 542-562. doi: 10.1016/S0749$596 \mathrm{X}(02) 00536-3$

Sturt, P. (2013). "Constraints on referential processing," in Sentence Processing, ed R. van Gompel (London: Routledge), 136-159.

Tang, C. C. J. (1989). Chinese reflexives. Nat. Lang. Linguist. Theory 7, 93-121. doi: $10.1007 / \mathrm{BF} 00141348$

Van Dyke, J. A. (2007). Interference effects from grammatically unavailable constituents during sentence processing. J. Exp. Psychol. Learn. Mem. Cogn. 33, 407-430. doi: 10.1037/0278-7393.33.2.407

Van Dyke, J. A., and Johns, C. L. (2012). Memory interference as a determinant of language comprehension. Lang. Linguist. Compass 6, 193-211. doi: $10.1002 /$ lnc3.330

Van Dyke, J. A., and Lewis, R. L. (2003). Distinguishing effects of structure and decay on attachment and repair: a cue-based parsing account of recovery from misanalyzed ambiguities. J. Mem. Lang. 49, 285-316. doi: 10.1016/S0749596X(03)00081-0

Van Dyke, J. A., and McElree, B. (2006). Retrieval interference in sentence processing. J. Mem. Lang. 55, 157-166. doi: 10.1016/j.jml.2006. 03.007

Van Dyke, J. A., and McElree, B. (2011). Cue-dependent interference in comprehension. J. Mem. Lang. 65, 247-263. doi: 10.1016/j.jml.2011. 05.002 
Van Gompel, R. P., and Majid, A. (2004). Antecedent frequency effects during the processing of pronouns. Cognition 90, 255-264. doi: 10.1016/S00100277(03)00161-6

Xiang, M., Dillon, B., and Phillips, C. (2009). Illusory licensing effects across dependency types: ERP evidence. Brain Lang. 108, 40-55. doi: 10.1016/j.bandl.2008.10.002

Xue, P., Pollard, C., and Sag, I. (1994). "A new perspective on Chinese ziji," in Proceedings of the 13th Annual Meeting of the West Coast Conference on Formal Linguistics (Stanford, CA: CSLI), 432-447.
Conflict of Interest Statement: The authors declare that the research was conducted in the absence of any commercial or financial relationships that could be construed as a potential conflict of interest.

Copyright $\odot 2016$ Dillon, Chow and Xiang. This is an open-access article distributed under the terms of the Creative Commons Attribution License (CC BY). The use, distribution or reproduction in other forums is permitted, provided the original author(s) or licensor are credited and that the original publication in this journal is cited, in accordance with accepted academic practice. No use, distribution or reproduction is permitted which does not comply with these terms. 